\title{
APLIKASI PENGELOLAAN KERJASAMA PEMBUATAN PROJEK PADA DINAS KOMUNIKASI DAN INFORMATIKA BANYUMAS
}

\author{
Irfan Agus Tiawan ${ }^{1,}$ Lasmedi Afuan*2 \\ 1,2Jurusan Informatika, Fakultas Teknik, Universitas Jenderal Soedirman \\ Email: ${ }^{1}$ agustiawanirfan866@gmail.com, ${ }^{2}$ lasmedi.afuan@ unsoed.ac.id
}

(Naskah masuk : 30 Juni 2020, diterima untuk diterbitkan : 06 Juli 2020)

\begin{abstract}
Abstrak
Penelitian ini mengembangkan sebuah aplikasi berbasis web. Aplikasi yang dikembangkan membantu Dinas Komunikasi dan Informatika (DINKOMINFO) Banyumas dalam pencatatan, pengarsipan, dan penyediaan informasi. Tujuan utama pengembangan aplikasi adalah untuk menjembatani antara developer dengan instansi daerah dalam proses kerja sama pembutan projek. Ada tiga tahapan yang dilakukan dalam pengembangan aplikasi yaitu tahapan pengumpulan data, tahapan analisis kebutuhan aplikasi, dan tahapan pengembangan aplikasi. Untuk tahapan pengumpulan data dilakukan dengan menggunakan metode wawancara dan observasi. Pengembangan aplikasi menggunakan metode pengembangan perangkat lunak Kanban. Aplikasi diimplementasikan menggunakan framework Laravel dengan bahasa pemrograman PHP. Untuk pengelolaan basisdata, aplikasi menggunakan Database Management System (DBMS) MySQL. Aplikasi yang telah dikembangakan dapat digunakan untuk menjembatani antara DINKOMINFO, instansi, dan developer dalam proses kerja sama pembuatan projek dengan memanfaatkan peran teknologi yang berbasis website.
\end{abstract}

Kata kunci: aplikasi, framework, kanban, Laravel, Mysql, PHP.

\section{APPLICATION OF MANAGEMENT PROJECT-COLLABORATION ON BANYUMAS COMMUNICATION AND INFORMATION OFFICE}

This research develops a web-based application. The developed application used to assist the Banyumas Communication and Information Office (DINKOMINFO) in recording, archiving, and providing information. The main purpose of application development is to bridge between developers and local agencies in the collaborative process of project development. There are three stages that are carried out in application development, namely the stage of data collection, the stage of application needs analysis, and the stage of application development. For the stage of data collection is done by using the method of interview and observation. Application development uses the Kanban software development method. The application is implemented using the Laravel framework with the PHP programming language. For database management, the application uses the MySQL Database Management System (DBMS). Applications that have been developed can be used to bridge between DINKOMINFO, agencies, and developers in the process of collaborating on making projects by utilizing the role of website-based technology.

Keywords: application, framework, kanban, Laravel, Mysql, PHP.

\section{PENDAHULUAN}

Dinas Komunikasi dan Informatika (DINKOMINFO) Banyumas merupakan sebuah instansi yang bertanggung jawab atas pengolahan informasi dalam lingkungan Pemerintahan di wilayah Banyumas. Berdasarkan Peraturan Bupati Banyumas No. 6 Tahun 2016 tentang Kedudukan Susunan Organisasi, Tugas dan Fungsi Serta Tata Kerja Dinas Komunikasi dan Informatika Kabupaten Banyumas adalah melaksanakan teknis operasional urusan pemerintahan daerah Bidang Komunikasi dan Informatika berdasarkan asas otonomi dan tugas pembantuan. Untuk melaksanakan tugas sebagaimana dimaksud di atas, Dinas Komunikasi dan Informatika Kabupaten Banyumas mempunyai fungsi salah satunya adalah memimpin penyelenggaraan koordinasi dan pelaksanaan kebijakan urusan pemerintahan bidang Komunikasi dan Informatika. Dalam menjalankan fungsi tersebut, DINKOMINFO Banyumas memiliki permasalahan yaitu 1) DINKOMINFO belum memiliki website repositori sotware apa saja yang telah dibuat; 2) DINKOMINFO belum memiliki website yang mampu menjadi alat koordinasi antara instansi dengan DINKOMINFO terkait pengajuan 
software; 3) DINKOMINFO belum memiliki website yang menjadi penghubung antara developer dengan DINKOMINFO.

Berdasarkan permasalahan di atas, DINKOMINFO Banyumas merumuskan pembuatan website kerjasama antara instansi pemerintah, swasta, dan individu dalam hal pengembangan project, yang diharapkan mampu menciptakan koordinasi yang baik antara instansi yang membutuhkan jasa pembuatan software dengan DINKOMINFO dan developer umum, menciptakan database repositori software sehingga para instansi yang membutuhkan software, yang kebetulan software diajukan memiliki fungsi yang sama dengan software yang telah diajukan oleh instansi lain.

\section{TINJAUAN PUSTAKA}

\subsection{Rancang bangun}

Rancang bangun merupakan serangkaian prosedur untuk menterjemahkan hasil analisa dari sebuah sistem ke dalam bahasa pemrograman untuk mendeskripsikan dengan detail bagaimana komponen-komponen sistem di implementasikan. Sedangkan pembangunan atau bangun sistem adalah kegiatan menciptakan sistem baru maupun mengganti atau memperbaiki sistem yang telah ada secara keseluruhan[1][2].

\subsection{Aplikasi}

Aplikasi adalah suatu subkelas software yang memanfaatkan kemampuan komputer langsung untuk melakukan suatu tugas tertentu yang diinginkan user [2][4] [5]. Pengembangan aplikasi sudah dilakukan oleh banyak peneliti diantaranya [6]-[12].

\subsection{Kanban}

Nama kanban berasal dari bahasa Jepang yang berarti "kartu penanda". Kanban adalah metodologi pengembangan perangkat lunak lean atau ramping yang berfokus pada pengiriman fungsionalitas dari aplikasi secara tepat waktu dan mengelola jumlah progres aplikasi yang sedang berjalan atau akan dikerjakan[3]

\subsection{Kerja sama}

Kerja sama adalah suatu bentuk proses sosial, dimana didalamnya terdapat aktivitas tertentu yang ditunjukkan untuk mencapai tujuan bersama dengan saling membantu dan saling memahami aktivitas masing-masing[13].

\section{$2.5 \mathrm{PHP}$}

PHP adalah sebuah bahasa scripting tingkat tinggi yang dipasang pada dokumen $H T M L$. Tujuan utama dari penggunaan bahasa pemrograan ini adalah untuk memungkinkannya membuat website yang dinamis[14].

\subsection{MYSQL}

MySQL merupakan perangkat lunak Database Management System (DBMS) yang tergolong dalam database server dan bersifat open source yang mempunyai struktur Relational Database Management System (RDBMS)[15].

\subsection{Framework}

Framework adalah sekumpulan perintah/fungsi dasar yang dapat membantu dalam menyelesaikan proses-proses yang lebih kompleks[16].

\section{METODE PENELITIAN}

Pada pengembangan aplikasi dibutuhkan tahapan penelitian. Metode penelitian yang digunakan dalam pengembangan aplikasi ini adalah Kanban Methodology, Gambar 1 menunjukan tahapan dari Kanban Methodology.

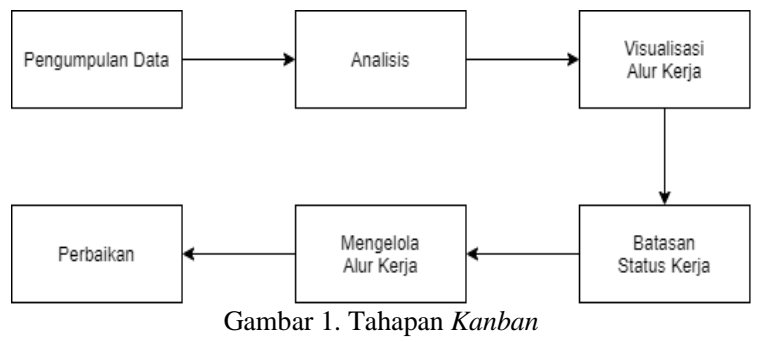

\subsection{Pengumpulan data}

Pada tahapan pengumpulan data, terdapat 2 (dua) cara yang digunakan yaitu wawancara dan observasi. Wawancara adalah metode pengumpulan informasi yang dilakukan dengan cara mengajukan pertanyaan kepada narasumber secara langsung untuk memperoleh data yang valid. Wawancara dilakukan kepada salah satu pegawai Dinas Komunikasi dan Informatika.

Pengamatan atau observasi adalah metode pengumpulan data yang dilakukan dengan cara mengamati suatu objek untuk kemudian memahami pengetahuan yang didapatkan dari sebuah fenomena untuk mendapatkan informasi yang dibutuhkan untuk keperluan tertentu.

\subsection{Analisis}

Data yang telah dikumpulkan pada tahap pengumpulan data akan dianalisis untuk mendapatkan hasil berupa alur kerja dan alur proses dari pengajuan kerja sama project, analisis kebutuhan pengguna, dan $U M L$. Hasil dari analisisi tersebut akan digunakan sebagai dasar dalam 
pengembangan sistem yang akan dilakukan pada tahapan selanjutnya.

\subsection{Visualisasi alur kerja}

Pada tahap pertama yang ada di Kanban methodology, visualisasikan setiap langkah kerja, komponen, proses yang harus dikerjakan untuk terciptanya sistem/aplikasi yang diinginkan client kedalam Kanban board. Ditahap ini dilakukan iterasi pengumpulan data, analisis, pengembangan, dan testing kedalam bagian backlog dalam Kanban board yang ditunjukkan oleh Gambar 2 .

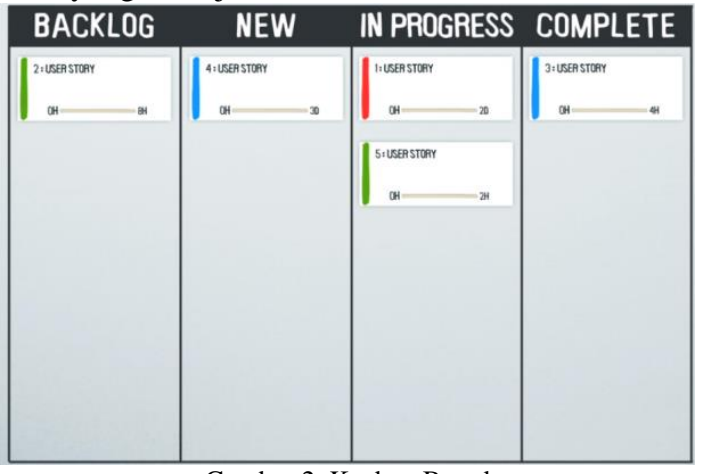

Gambar 2. Kanban Board

\subsection{Batasan status serja}

Batas status kerja adalah menetapkan batas maksimal tugas yang diperbolehkan dalam satu kolom status kerja. Batas ini dicantumkan pada Kanban board dan setiap anggota tim harus mematuhi batas maksimal tersebut.

\subsection{Mengelola alur kerja}

Prinsip mengelola aliran kerja adalah menjaga fokus pada tugas yang ada. Pada beberapa praktiknya, untuk menjaga kekonsistensian alur kerja adalah dengan memastikan semua tugas yang diperlukan dalam pengembangan aplikasi tercantum pada Kanban board dan mengerjakan proses yang hanya terdapat pada Kanban board saja sampai proses tersebut benar-benar selesai.

\subsection{Perbaiki}

Proses perbaikan dilakukan setelah proses atau fungsi yang telah dibuat dirasa selesai. Sebelum proses ini dijalankan, perlu dilakukan pengiriminan fungsionalitas kepada client terlebih dahulu, apakah hal tersebut sudah sesuai dengan yang diinginkan atau belum. Jika belum, maka proses tersebut masuk kedalam tahap perbaikan sampai memenuhi keinginan client namun tetap dengan perjanjian yang berlaku.

\section{HASIL DAN PEMBAHASAN}

\subsection{Pengumpulan data}

Padah tahapan pengumpulan data didapatkan informasi mengenai hasil diskusi yang ditunjukkan pada Tabel 1.

\begin{tabular}{|c|c|c|c|}
\hline No & Pengguna & Kebutuhan & Alasan \\
\hline 1 & Admin & $\begin{array}{l}\text { Tampilan } \\
\text { menarik, simple } \\
\text { dan informatif } \\
\text { Hanya admin } \\
\text { yang bisa } \\
\text { membuat akun } \\
\text { untuk instansi }\end{array}$ & $\begin{array}{l}\text { Agar tidak bosan } \\
\text { ketika melihat lama } \\
\text { utama } \\
\text { Agar terkoordinir } \\
\text { dan mencegah } \\
\text { kepalsuan yang } \\
\text { dibuat oleh pihak } \\
\text { tidak } \\
\text { bertanggungjawab } \\
\text { Karena } \\
\text { DINKOMINFO } \\
\text { menggambarkan } \\
\text { instansi tidak terlalu } \\
\text { paham tentang } \\
\text { software sehingga } \\
\text { DINKOMINFO } \\
\text { yang bertugas } \\
\text { menjembatani }\end{array}$ \\
\hline 2 & Pengembang & $\begin{array}{l}\text { Halaman dibuat } \\
\text { simple saja dan } \\
\text { tidak sama } \\
\text { dengan tema } \\
\text { yang diterapkan } \\
\text { pada laman } \\
\text { Admin } \\
\text { Mampu } \\
\text { mendaftar di } \\
\text { pengembangan } \\
\text { software yang } \\
\text { telah } \\
\text { dimasukkan ke } \\
\text { pengembangan } \\
\text { umum }\end{array}$ & $\begin{array}{l}\text { Karena laman admin } \\
\text { memiliki banyak } \\
\text { fungsi sedangkan } \\
\text { pengembang lebih } \\
\text { sedikit }\end{array}$ \\
\hline 3 & Instansi & $\begin{array}{l}\text { Tidak bisa untuk } \\
\text { mengedit akun }\end{array}$ & $\begin{array}{l}\text { Agar data tetap valid } \\
\text { dengan data yg } \\
\text { dimiliki } \\
\text { DINKOMINFO }\end{array}$ \\
\hline
\end{tabular}

\subsection{Analisis}

Pada tahap ini data yang telah didaptkan akan dipilah dan diubah kedalam $U M L$. Kebutuhan pengguna ini diubah menjadi bentuk karakteristik dari sistem sebelum dilakukan konstruksi. Pada tahapan ini terbagi menjadi perancangan Entity Relationship Diagram (ERD), Activity Diagram, Use case, Sequence Diagram dan Class Diagram.

a. Entity Relationship Diagram

Entity Relationship Diagram (ERD) merupakan sebuah diagram yang menggambarkan hubungan entitas dan relasi yang ada pada aplikasi. ERD dari aplikasi pengelolaan kerja sama pengajuan project ditunjukan oleh Gambar 3. 


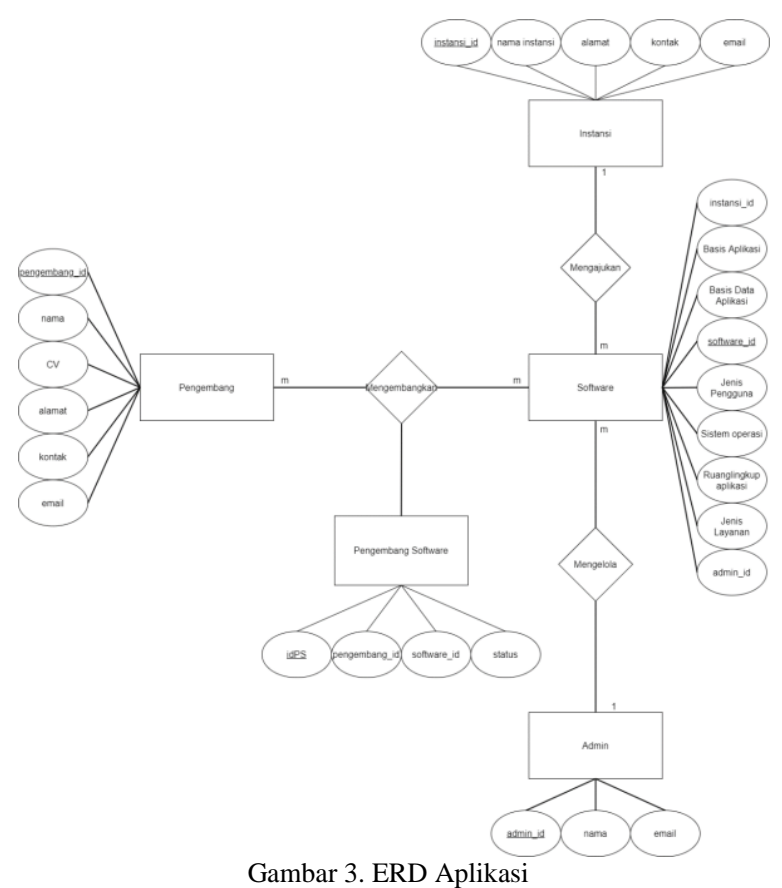

\section{b. Use Case Diagram}

Use case adalah sebuah diagram yang dibuat untuk menggambarkan actor dengan proses yang ada dalam aplikasi pengelolaan kerja sama pengajuan project. Gambar 4 menunjukkan Use case dari proses yang terjadi didalam aplikasi ini.

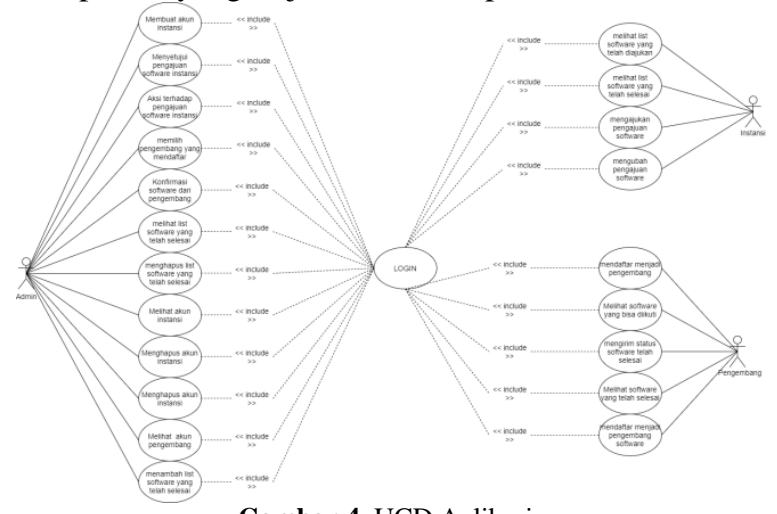

Gambar 4. UCD Aplikasi

\subsection{Visualisasi alur kerja}

Pada tahap visualisasi alur kerja, penulis melakukan pendefinisian Backlog yang diperlukan untuk membuat suatu aplikasi. Backlog tersebut didapatkan dari tahap pendefinisian User Requirement dan kemudian memasukkannya kedalam Kanban board. Tools yang digunakan sebagai kanban board atau tempat menempelkan Backlog adalah sebuah tools yang berbasis website bernama Trello. Backlog yang tercatat dalam Trello dapat ditunjukan oleh Gambar 5.

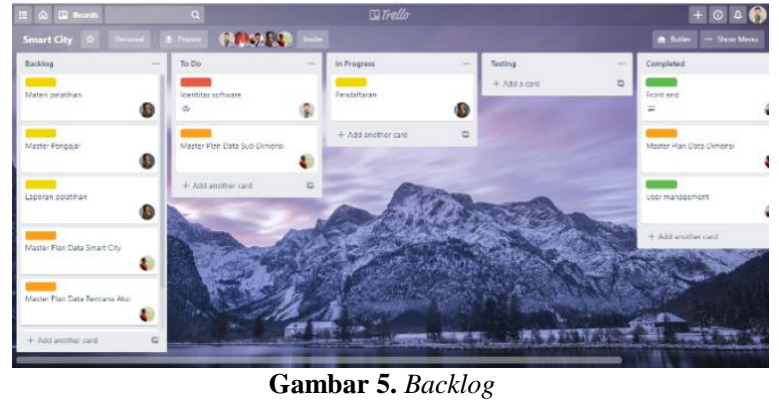

\subsection{Batasan status kerja}

Pembatasan status kerja dalam praktinya di pembuatan aplikasi pengelolaan kerja sama adalah men-setting To Do dari masing-masing tim adalah 2(dua) proses saja dan tidak boleh lebih dalam 2(dua) minggu. Batasan status kerja lainnya adalah deadline proses yang harus dikerjakan dan tidak boleh melewati waktu deadline tersebut. Orang yang bertugas memberikan batasan status kerja adalah Bapak Hendriarto Wigunawan, beliau akan ikut bergabung pada laman Trello dan bertindak sebagai Project Manager. Beliau akan memberikan batasan status kerja dari masing-masing To Do didalam deskripsinya dan penulis sebagai developer harus menaati apa yang telah di-setting oleh Project Manager.

\subsection{Mengelola alur kerja}

Seperti yang telah dijelaskan sebelumnya pada konsep mengelola alur kerja, bahwa prinsip dari mengelola alur kerja adalah fokus terhadap tugas yang ada. Tim yang ada dalam project management tetap fokus terhadap tugas yang diserahkan kepada masing-masing orang dan fokus terhadap batas status kerja. Kemudian dalam praktiknya, project manager meminta penulis untuk selalu menyampaikan perkembangan dalam pengerjaan fungsionalitas dari aplikasi melalui aplikasi Trello selama masa kerja praktik berlangsung.

\subsection{Perbaiki}

Tahap perbaikan baru bisa dilakukan apabila client telah melihat keseluruhan atau sebagian aplikasi yang telah dikembangkan baik dari design interface maupun proses didalam aplikasi. Berikut adalah gambar-gambar dari wireframe dan design interface beserta kode program yang telah dibuat dari beberapa proses yang ada dalam aplikasi pengelolaan kerja sama pengajuan software, dimulai dari admin, instansi, kemudian pengembang. Berikut adalah rancangan wireframe dari interface halaman Admin yang ditunjukkan oleh Gambar 6, wireframe halaman Pengembang yang ditunjukkan oleh Gambar 7, dan wireframe halaman Instansi yang ditunjukkan oleh Gambar 8. 


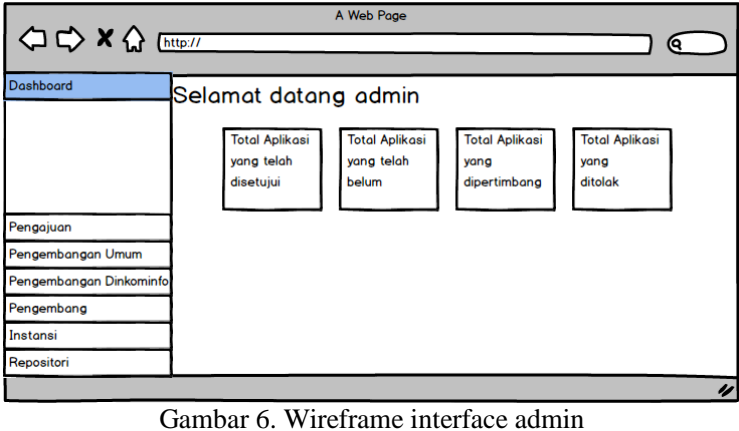

Gambar 6. Wireframe interface admin



Gambar 7. Wireframe interface pengembang

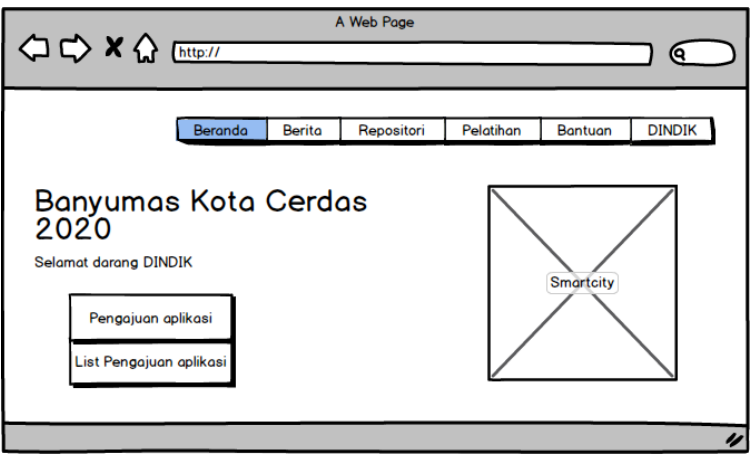

Gambar 8. Wireframe interface instansi

Apabila perancangan wireframe telah selesai, maka tahapan selanjutnya dalam implementasi ke dalam bahasa pemrograman. Hasil implementasi wierframe halaman admin (Gambar 6) ditunjukkan oleh Gambar 9.

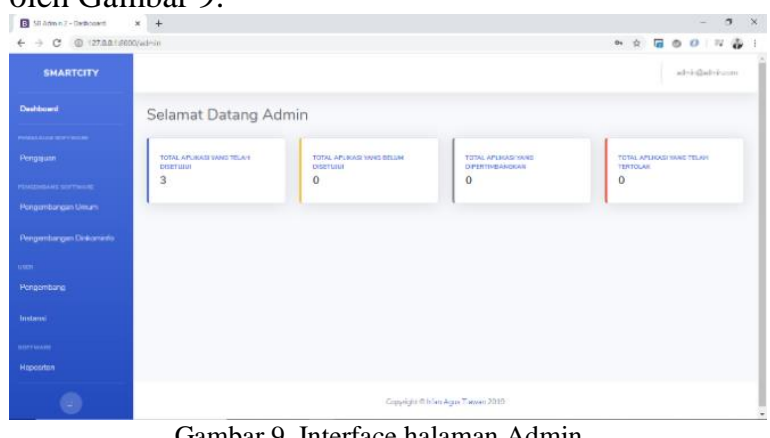

Gambar 9. Interface halaman Admin

Kemudian pada halaman utama pengembang, terdapat navbar yang mengarahkan pengembang untuk melihat aplikasi yang bisa diikuti. Halaman utama pengembang merupakan hasil implementasi dari wireframe yang ditampilkan pada Gambar 7 dan Gambar 8.

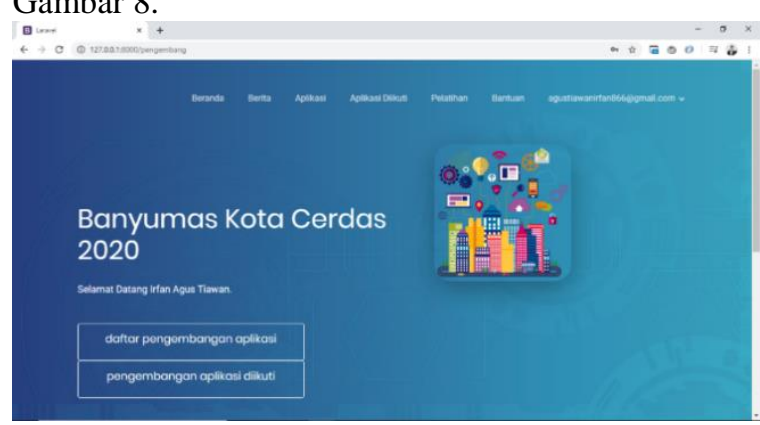

Gambar 8. Interface halaman pengembang

Sedangkan pada halaman instansi disediakan form pengajuan software. Form tersebut ditujukan agar instansi daerah yang ingin memiliki sebuah software agar mengisinya dan nantinya dari DINKOMINFO akan menyetujui atau menolaknya. Halaman form pengajuan software instansi ditunjukkan pada Gambar 9.

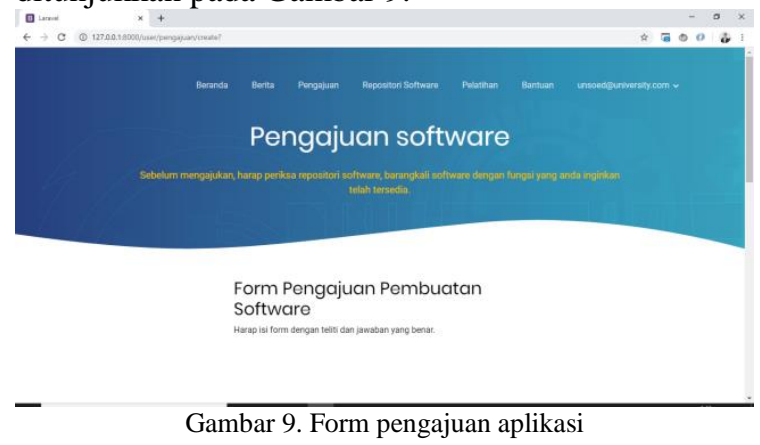

\subsection{Pengujian Aplikasi}

Tabel 2. Hasil Pengujian Blackbox

\begin{tabular}{|c|c|c|c|c|}
\hline No & $\begin{array}{c}\text { Fungsi yang } \\
\text { diuji }\end{array}$ & Input & Output & Status \\
\hline 1. & Menu Beranda & $\begin{array}{l}\text { Klik m } \\
\text { beranda }\end{array}$ & $\begin{array}{l}\text { menu Menampilkan } \\
\text { halaman utama } \\
\text { aplikasi }\end{array}$ & Valid \\
\hline 2. & $\begin{array}{l}\text { Menu } \\
\text { Pengajuan }\end{array}$ & $\begin{array}{l}\text { Klik m } \\
\text { pengajuan }\end{array}$ & $\begin{array}{l}\text { menu Menampilkan } \\
\text { form pengajuan } \\
\text { pembuatan } \\
\text { software }\end{array}$ & Valid \\
\hline 3. & $\begin{array}{l}\text { Menu Daftar } \\
\text { pengembangan } \\
\text { aplikasi }\end{array}$ & $\begin{array}{l}\text { Klik m } \\
\text { Daftar } \\
\text { pengemban } \\
\text { aplikasi }\end{array}$ & $\begin{array}{l}\text { menu Menampilkan } \\
\text { halaman datar } \\
\text { angan pengembangan } \\
\text { aplikasi }\end{array}$ & Valid \\
\hline 4. & $\begin{array}{l}\text { Menu } \\
\text { pengembangan } \\
\text { aplikasi diikuti }\end{array}$ & $\begin{array}{l}\text { Klik m } \\
\text { pengemban } \\
\text { aplikasi }\end{array}$ & $\begin{array}{l}\text { menu Menampilkan } \\
\text { angan menu } \\
\text { pengembangan } \\
\text { aplikasi }\end{array}$ & Valid \\
\hline
\end{tabular}

Pengujian ini dilakukan untuk melihat kinerja dari aplikasi yang telah dikembangkan. Pengujian 
aplikasi menggunakan metode Blackbox Testing. Blackbox Testing merupakan metode pengujian perangkat lunak yang digunakan untuk menguji perangkat lunak tanpa mengetahui struktur internal program atau hanya mengamati fungsional dan eksekusi dari software. Pengujian blackbox testing dapat dilihat pada Tabel 2.

\section{KESIMPULAN}

Aplikasi yang dikembangkan dapat digunakan untuk menjembatani antara DINKOMINFO, instansi, dan developer dalam proses pembuatan kerja sama dapat dilakukan dengan memanfaatkan peran teknologi yang berbasis website. Selain itu, merancang dan membangun sebuah aplikasi dengan metode yang baik dan benar dapat mengefisienkan waktu dan biaya.

\section{DAFTAR PUSTAKA}

[1] N. . H, Rancang Bangun Aplikasi Multiplatform. Informatika Bandung, 2015.

[2] Jogiyanto, Analisis dan Desain Sistem Informasi: Pendekatan Terstruktur Teori dan Praktik Aplikasi Bisnis. Andi, 2005.

[3] J. Ahmad, A. ul Hasan, T. Naqvi, and T. Mubeen, "A Review on Software Testing and Its Methodology," Manag. J. Softw. Eng., vol. 13, no. 1, pp. 32-38, 2019, doi: 10.26634/jse.13.3.15515.

[4] H. Kniberg and M. Skarin, Kanban and Scrum - making the most of both, vol. 1, no. 1/November. C4Media, 2010.

[5] L. Afuan, I. Permadi, and N. Hidayat, "Rancang Bangun Aplikasi Berbasis Teknologi WAP Sebagai Media Promosi Komoditas Pariwisata di Banyumas," $J$. Telemat., vol. 2, no. 2, pp. 12-34, 2009.

[6] S. Kosasi, "PEMBUATAN SISTEM INFORMASI PENJUALAN BERBASIS WEB UNTUK MEMPERLUAS PANGSA PASAR Sandy," Pembuatan Sist. Inf. Penjualan Berbas. Web Untuk Memperluas Pangsapasar, pp. 225-232, 2014.

[7] P. D. Astuti, "Sistem Informasi Penjualan Obat Pada Apotek Jati Farma Arjosari," Indones. J. Comput. Sci. - Speed 16 FTI UNSA Vol 10 No 1 - Mei 2013 ijcss.unsa.ac.id, vol. 10, no. 1, pp. 142-147, 2013, doi: http://dx.doi.org/10.3112/speed.v3i4.1217.

[8] J. Bernadi, “Aplikasi Sistem Informasi Penjualan Berbasis Web pada Toko Velg YQ," ComTech Comput. Math. Eng. Appl., vol. 4, no. 2, p. 731, 2013, doi: 10.21512/comtech.v4i2.2504.

[9] A. Sinsuw and X. Najoan, "Prototipe Aplikasi Sistem Informasi Akademik Pada Perangkat Android," E-Journal Tek. Elektro Dan Komput., vol. 2, no. 5, pp. 21-30, 2013, doi: 10.35793/jtek.2.5.2013.4291.

[10] R. V. Imbar and B. S. Hartanto, "Aplikasi Sistem Informasi Sumber Daya Manusia dengan Fitur DSS Menggunakan Metode Topsis pada PT . X," J. Sist. Inf., pp. 125144, 2008.

[11] A. Budiman and A. Mulyani, "Rancang Bangun Aplikasi Sistem Informasi Persedian Barang di TB. Indah Jaya Berbasis Desktop," J. Algoritm., vol. 13, no. 2, pp. 374-378, 2017, doi: 10.33364/algoritma/v.13-2.374.

[12] W. Welda and B. A. Minartiningtyas, "Sistem Informasi Pengelolaan Kerjasama Bidang Humas pada STMIK STIKOM Indonesia," J. Sisfokom (Sistem Inf. dan Komputer), vol. 6, no. 2, p. 86, 2017, doi: 10.32736/sisfokom.v6i2.252.

[13] D. Setiawan, Buku Sakti Pemrograman Web. Start Up, 2017.

[14] E. F. Wati and A. A. Kusumo, "Penerapan Metode Unified Modeling Language (UML) Berbasis Desktop Pada Sistem Pengolahan Kas Kecil Studi Kasus Pada PT Indo Mada Yasa Tangerang," UNSIKA Syntax J. Inform., 2016.

[15] J. Widom, H. García-Molina, and J. Ullman, Database Systems: The Complete Book. Pearson Prentice Hall, 2001.

[16] R. S. Pressman, Rekayasa Perangkat Lunak Pendekatan Praktisi Edisi 7 (Buku Satu). Andi, 2010. 